\title{
Controle de nabo e azevém em trigo com herbicidas pós-emergentes
}

\section{Control ryegrass and wild radish in wheat with post-emergent herbicides}

\author{
Cleudson José Michelon' \\ Leandro Costa ${ }^{2}$ \\ Lucimara Rodrigues Padilha ${ }^{3}$ \\ Rudinei Balem ${ }^{4}$
}

\section{RESUMO}

A coexistência de plantas daninhas nos estádios inicias de desenvolvimento na cultura de trigo, reduzem o potencial produtivo da cultura refletindo no menor rendimento de grãos. Nesse sentido, o objetivo do presente trabalho foi avaliar o controle de azevém (Lolium multiflorum) e nabo (Raphanus raphanistrum L.) com a utilização de herbicidas aplicados em pós-emergência em duas cultivares de trigo, além de mensurar o efeito fitotóxico dos herbicidas sobre a cultura. 0 experimento teve os seguintes tratamentos: Clodinafope-propargil, Pinoxadene, Iodosulfurom-metílico e Pyroxsulam, nas dosagens recomendadas pelo fabricante, 25\% a menos e $25 \%$ a mais da dose recomendada. A aplicação dos herbicidas ocorreu no estádio de perfilhamento do trigo, com pulverizador pressurizado por $\mathrm{CO}_{2}$, pontas tipo jato leque plano simples, da série 11002, com vazão de $150 \mathrm{~L} \mathrm{ha}^{-1}$. As avaliações foram realizadas aos 7, 14, 21 e 28 dias após aplicação (DAA), emitindo uma nota de fitotoxidade, sendo 0 com ausência de fitotoxidade e 100 com a máxima fitotoxidade (morte de planta). Os resultados obtidos foram submetidos à análise de variância e às médias comparadas pelo teste de tukey a $5 \%$ de significância. A fitotoxidade foi notória apenas nos 7 DAA. O herbicida Pinoxadene propiciou o melhor controle de azevém e foi o tratamento em que a cultura do trigo apresentou o maior rendimento de grãos. O percentual de fitotoxidez foi estável entre cultivares, sendo a característica de fitotoxidez atrelada a produtos.

Palavras-chave: Triticum aestivum. Graminicidas. Competição.

\footnotetext{
1 Instituto Federal Farroupilha - Campus São Vicente do Sul | cleudson.michelon@iffarroupilha.edu.br

2 Instituto Federal Farroupilha - Campus Júlio de Castilhos | leandro.costa@iffarroupilha.edu.br

3 Instituto Federal Farroupilha - Campus Júlio de Castilhos | luci.rpadilha@gmail.com

4 Instituto Federal Farroupilha - Campus São Vicente do Sul | rudineiecosysten@gmail.com
} 


\section{Controle de nabo e azevém em trigo}

com herbicidas pós-emergentes

Control ryegrass and wild radish in wheat

with post-emergent herbicides

\section{ABSTRACT}

The coexistence of weeds in the early stages of development in wheat reduces the productive potential of the crop, reflecting in lower grain yield. In this sense, the objective of this work was to evaluate the control of Ryegrass (Lolium multiflorum) and wild radish (Raphanus raphanistrum L.) with the use of post-emergency herbicides applied in two wheat cultivars, in addition was measured the phytotoxic effect of herbicides on wheat crop. The experiment had the following treatments: Clodinafop-propargyl, Pinoxaden, lodosulfuron-methyl and Pyroxsulam in the dosages recommended by the manufacturer $25 \%$ less and $25 \%$ more than the recommended dose. The application of herbicides occurred in the wheat tillering stage, with $\mathrm{CO}_{2}$ pressurized sprayer, and simple flat fan type tips, series 11002 , with a flow rate of $150 \mathrm{~L} \mathrm{ha}^{-1}$. The evaluations were performed at 7, 14, 21 and 28 days after application (DAA), issuing a phytotoxicity note, 0 with no phytotoxicity and 100 with the maximum phytotoxicity (plant death). The results obtained were submitted to analysis of variance and the means compared by the tukey test at $5 \%$ significance. Phytotoxicity was only evident in the 7 DAA. The herbicide pinoxaden provided the best control of ryegrass and was the treatment in which the wheat crop showed the highest grain yield. The percentage of phytotoxicity was stable between cultivars, and the phytotoxicity characteristic was linked to products.

Keywords: Triticum aestivum. Graminicides. Competition. 


\section{Introdução}

No ano de 2017, a produtividade média de trigo brasileira foi de $2542 \mathrm{~kg} \mathrm{ha}^{-1}$, (IBGE, 2017). Esse número pode ser mais expressivo nas regiões produtoras do país, porém a coexistência de plantas daninhas nos estádios inicias de desenvolvimentos na cultura de trigo é um dos fatores que refletem no menor rendimento de grãos. De acordo com Silva et al. (2016), a presença de nabo (Raphanus raphanistrum L.) na lavoura de trigo com até 24 dias após a emergência, ocasiona redução de produtividade do trigo.

A mato-competição estabelece interações entre a cultura e a invasora, ao ponto de haver competição por água, radiação solar e nutrientes. Estudo realizado por Lamego et al. (2015), mostrou que a altura da planta de trigo foi de $36 \%$ maior quando submetida à competição com azevém (Lolium multiflorum), reduzindo assim o número de perfilhos e o rendimento de grãos, sendo a deficiência luminosa o fator responsável por esse resultado. Nessa linha, Costa \& Rizzardi (2015) relatam que o nabo possui habilidade competitiva superior à cultura do trigo e sua presença na lavoura implica menor potencial produtivo da mesma.

Os herbicidas utilizados em pós-emergência na cultura do trigo no Sul do Brasil, predominantemente, pertencem ao grupo das ACCASE (inibição da enzima Acetil Coenzima-A Carboxilase) e ao grupo da ALS (inibidores da enzima Acetolactato Sintase). Os inibidores da enzima ALS causam inibição da síntese dos aminoácidos ramificados (leucina, isoleucina e valina), através da inibição da enzima Aceto Lactato Sintase (ALS), interrompendo a síntese proteica que, por sua vez, interfere na síntese do DNA e no crescimento celular. Os herbicidas inibidores da enzima ACCASE são rapidamente absorvidos pelas folhas e atingem os meristemas da planta, apesar da quantidade que atinge a área meristemática ser muito pequena em relação ao que é aplicado (FERREIRA et al., 2005).

O uso repetitivo de princípios ativos pertencentes a esses grupos resultou no surgimento de plantas resistentes de difícil ou ineficiente controle químico. Além disso, algumas espécies possuem alta habilidade de multiplicação das plantas resistentes, o que torna o problema ainda maior. Nesse sentido, Vargas et al. (2015) estudando o cruzamento genético de azevém resistente ao herbicida lodosulfuron-methyl (ALS), observaram que a evolução da resistência ocorreu rapidamente na população desta gramínea.

Estudos conduzidos por Ulzurrumet et al. (2012) demonstraram que a população de azevém apresentou alto nível de resistência à variação de doses testadas do herbicida Pyroxsulam (ALS). Porém, esse mesmo estudo não mostrou resistência ao herbicida Pinoxadene (ACCASE) na população de azevém avaliada.

De modo geral, as cultivares de trigo apresentam boa tolerância aos herbicidas comumente utilizados. Entretanto, algumas limitações, como a falta de entendimento da funcionalidade dos mecanismos de ação, aplicações nas condições climáticas e no estádio de desenvolvimento das plantas daninhas inadequados e a presença de espécies resistentes, podem reduzir a eficiência do manejo químico. Nessas situações, a tendência é um aumento nas dosagens dos herbicidas objetivando a melhor eficácia de controle, o que poderá trazer como consequências, além da elevação dos custos de produção, o aumento do risco de fitotoxidez, como a verificada para os herbicidas lodosulfuron-methyl (ALS) e 2,4D que reduziram o teor de clorofila e carotenóides no trigo em trabalhos conduzido por Agostinetto et al. (2016).

No cenário em que plantas de azevém e nabo passam a desenvolver resistência aos herbicidas comumente utilizados, surge a necessidade de pesquisar novos mecanismos químicos de controle. Além disso, novas cultivares de trigo são lançadas anualmente e poderá haver diferentes tolerâncias aos herbicidas. 
Assim, o objetivo desse trabalho foi avaliar o controle de azevém e nabo forrageiro com a utilização de herbicidas aplicados em pós-emergência em duas cultivares de trigo, além de mensurar o efeito fitotóxico dos herbicidas sobre a cultura.

\section{Material e métodos}

O trabalho foi realizado no ano de 2017, no Centro de Pesquisa de Sementes (DDPA/SEAPI), localizado em Júlio de Castilhos - RS. O local possui altitude de 477 metros (m) e solo classificado como ARGISSOLO VERMELHO Distrófico arênico (EMBRAPA, 2018). De acordo com a classificação de Köeppen, o tipo climático predominante na região de Júlio Castilhos é o cfb.

Os tratamentos utilizados compreenderam os herbicidas para controle de plantas daninhas em pós-emergência na cultura do trigo, associados aos seus respectivos adjuvantes recomendados pelos fabricantes. 0 delineamento experimental utilizado foi de blocos casualisados dispostos em esquema trifatorial (cultivares $x$ produtos $x$ doses), com três repetições. $O$ fator $A$ consistiu de duas cultivares de trigo TBIO Toruk e TBIO Audaz; o fator B foram 4 herbicidas (Iodosulfurom-metílico, Pyroxsulam, Clodinafope-propargil e Pinoxadene); e o fator C, 4 doses (0\% testemunha, 75\% da dose comercial, $100 \%$ da dose comercial e $125 \%$ da dose comercial, recomendada pelo fabricante), conforme detalhado na Tabela 1.

Juntamente com os herbicidas, foram adicionados adjuvantes recomendados pelos fabricantes para cada produto. Assim, adicionaram-se os adjuvantes Hoefix $\left(0,45 L \mathrm{ha}^{-1}\right)$ e Veget oil $\left(0,5 \mathrm{~L} \mathrm{ha} \mathrm{h}^{-1}\right)$, respectivamente, para os herbicidas lodosulfurom-metílico e Pyroxsulam e Nimbus $\left(0,75 \mathrm{~L} \mathrm{ha}^{-1}\right)$ para os herbicidas Clodinafope-propargil e Pinoxadene.

Tabela 1 - Herbicidas, mecanismo de ação e doses utilizadas em pós-emergência na cultura do trigo

\begin{tabular}{l|c|c|c|c|c}
\hline \multicolumn{1}{c|}{ Tratamentos } & Mecanismo de ação & $\begin{array}{c}\text { Dose 1 } \\
(0 \%)\end{array}$ & $\begin{array}{c}\text { Dose 2* } \\
(75 \%)\end{array}$ & $\begin{array}{c}\text { Dose 3* } \\
(100 \%)\end{array}$ & $\begin{array}{c}\text { Dose } 4^{*} \\
(125 \%)\end{array}$ \\
\hline lodosulfurom-metílico & Inibidor de ALS & 0 & 0,075 & 0,1 & 0,125 \\
\hline Pyroxsulam & Inibidor de ALS & 0 & 0,3 & 0,4 & 0,5 \\
\hline Clodinafope-propargil & Inibidor de ACCase & 0 & 0,187 & 0,25 & 0,312 \\
\hline Pinoxadene & Inibidor de ACCase & 0 & 0,375 & 0,5 & 0,625 \\
\hline
\end{tabular}

*Dose em L hä-1 ou kg ha-1. Fonte: elaborada pelos autores

A semeadura das cultivares foi realizada no dia 21 de junho de 2017, no sistema de cultivo plantio direto, com semeadora Semeato (PD 17) de 18 linhas e espaçamento entre linhas de $0,17 \mathrm{~m}$. O histórico de cultivos do local consiste em uma sucessão de soja no verão e trigo no inverno. A área foi manejada com os herbicidas Glifosato ( $\left.\mathrm{L} \mathrm{ha}^{-1}\right)$ e Cletodim $\left(0,4 \mathrm{~L} \mathrm{ha} \mathrm{a}^{-1}\right)$ para controle das gramíneas já emergidas. 0 herbicida Paraquat $(2 \mathrm{~L} \mathrm{ha-1})$ foi aplicado três dias antes da semeadura, com o objetivo de erradicar a totalidade de plantas invasoras na área. Os demais manejos de doenças e pragas seguiram as recomendações técnicas para a cultura.

As unidades experimentais (parcelas) possuíam 3,06 m de largura (18 linhas de trigo) e 2,5 m de comprimento. Além das parcelas testemunhas (sem aplicação de herbicidas) também foram preservadas 3 linhas em cada parcela em que não foi realizada a pulverização, visando facilitar a avaliação visual de fitotoxidez localmente.

As aplicações dos herbicidas em pós-emergência foram realizadas quando as cultivares estavam no início do perfilhamento. As testemunhas foram consideradas como dose zero, sendo estas parcelas pulverizadas somente com água, com volume de calda de $150 \mathrm{~L} \mathrm{ha-1}$. As espécies de plantas daninhas avaliadas foram o azevém e o nabo. 
As aplicações ocorreram das 15 até as 16 horas do dia e as condições meteorológicas durante as aplicações foram amenas, com temperatura do ar de $17^{\circ} \mathrm{C}$, umidade relativa de $70 \%$, e o velocidade do vento de 4,2 $\mathrm{km} \mathrm{h}^{-1}$.

As avaliações para verificar o controle de azevém e nabo foram realizadas aos 7, 14, 21 e 28 dias após a aplicação (DAA), sendo estas baseadas em escalas visuais, onde zero corresponde a $0 \%$ de controle e as plantas totalmente controladas receberam a nota igual a 100\% de controle. Para essas quantificações, foram levadas em consideração folhas das plantas invasoras com injúrias, clorose e plantas mortas, com o meristema principal do caule de fácil remoção com as mãos.

As plantas de nabo foram retiradas manualmente das parcelas tratadas com Pinoxadene e Clodinafope-propargil, deixando qualquer relação de competição com o trigo a cargo das plantas de azevém presentes na área, permitindo assim avaliar a competição de plantas de mesma família da cultura de interesse, pelo fato de que estes herbicidas não estabelecerem nenhuma ação para esse grupo de invasoras.

Para determinar o efeito fitotóxico na cultura, foram realizadas avaliações visuais também aos 7, 14, 21 e 28 DAA, levando em consideração as características que evidenciam tal reação dos herbicidas nas plantas, como queima de folhas e caules, clorose nas folhas e morte de plantas. No presente trabalho, somente foi avaliada a clorose e, como parâmetro dessa avaliação, adotou-se a escala adaptada da European Weed Research Council (EWRC, 1964) em percentual (\%), onde zero significa nenhum efeito de fitotoxidade e 100 a morte das plantas (Tabela 2). Com uso da escala, o avaliador posicionava-se em frente a cada parcela e redigia uma nota, comparando-as sempre com a avaliação da testemunha que recebeu somente a pulverização de água. A altura de plantas foi mensurada com um auxílio de uma trena, sendo realizada em três plantas de trigo em cada parcela, aos 14 DAA e aos 28 DAA.

Tabela 2 - Escala de fitotoxidade utilizada nas avaliações do experimento de herbicidas em pós-emergência

\begin{tabular}{c|c|c}
\hline Fitotoxidade & Escala (\%) & Descrição \\
\hline Ótimo & 0 a 5 & Sem/leve fitotoxidade \\
\hline Bom & 0 a 25 & Fitotoxidade aceitável \\
\hline Regular & 26 a 60 & Fitotoxidade não aceitável \\
\hline Ruim & 61 a 100 & Planta totalmente morta \\
\hline
\end{tabular}

Fonte: adaptada de EWRC, (1964)

A colheita ocorreu no mês de novembro, na maturação fisiológica de cada cultivar, onde foi quantificado o rendimento de grãos, peso de mil grãos (PMG) e o peso hectolitro (Ph). Os dados foram submetidos à análise de variância pelo Teste $\mathrm{F}$ a $5 \%$ de probabilidade com o auxílio do software Sisvar ${ }^{\circledR}$ e apresentando significância, as variáveis qualitativas foram comparadas pelo teste Tukey e quantitativas foram submetidas à análise de regressão.

\section{Resultados e discussão}

\subsection{Controle de Raphanus raphanistrum L.}

Não houve interação significativa entre os fatores avaliados para nenhum parâmetro estudado. 0 herbicida Pyroxsulam foi o que apresentou o melhor controle de nabo, diferindo estatisticamente de lodosulfurom-metílico aos 7, 14 e 21 DAA (Tabela 3). 
Tabela 3 - Percentual de controle de nabo aos 7, 14, 21 e 28 dias após a aplicação (DAA) dos herbicidas

\begin{tabular}{l|c|c|c|c}
\hline \multicolumn{1}{c|}{ Tratamentos } & 7 DAA & 14 DAA & 21 DAA & 28 DAA \\
\hline Testemunha & $0 \mathrm{a}$ & $0 \mathrm{a}$ & $0 \mathrm{a}$ & $0 \mathrm{a}$ \\
\hline Pinoxadene & $0 \mathrm{a}$ & $0 \mathrm{a}$ & $0 \mathrm{a}$ & $0 \mathrm{a}$ \\
\hline Clodinafope-propargil & $0 \mathrm{a}$ & $0 \mathrm{a}$ & $0 \mathrm{a}$ & $0 \mathrm{a}$ \\
\hline lodosulfurom-metílico & $61,5 \mathrm{~b}$ & $66,9 \mathrm{~b}$ & $71,2 \mathrm{~b}$ & $62,5 \mathrm{~b}$ \\
\hline Pyroxsulam & $64,0 \mathrm{c}$ & $69,5 \mathrm{c}$ & $75 \mathrm{c}$ & $62,5 \mathrm{~b}$ \\
\hline CV \% & 5,30 & 6,20 & 2,79 & 0,20 \\
\hline
\end{tabular}

Médias seguidas pelas mesmas letras não diferem estatisticamente. Fonte: elaborada pelos autores

Aos 28 DAA, ambos os herbicidas apresentaram 62,5\% de controle, sendo esses valores inferiores aos verificados para a avaliação de 21 DAA, demonstrando a capacidade de rebrote de algumas plantas. Outra possibilidade de baixa eficácia de controle é a presença de nabo resistente a este grupo de herbicidas. Nesse sentido, Cechin et al. (2016) identificaram biótipos de nabo com resistência cruzada a herbicidas inibidores da enzima ALS, e observaram que o controle mais eficiente dessa planta se deu com herbicidas de outros mecanismos de ação. A utilização de $100 \%$ da dose recomendada apresentou os melhores resultados no controle das plantas de nabo (Figura 1).

A elevação da dose em $25 \%$ em relação à recomendada pelo fabricante (125\%) demonstrou apenas um leve incremento no controle sobre a cultura do nabo no início do desenvolvimento, não justificando sua utilização. Uma alternativa para melhorar a eficácia dos produtos consiste na utilização de um sistema de rotação de culturas, pois permite rotacionar os herbicidas no sistema produtivo, reduzindo a seleção de mutações resistentes (ZELAYA, et al., 2004). Dessa forma, o controle será efetivado com mais eficiência com o uso da dosagem recomendada pelo fabricante.

Figura 1 - Controle de nabo utilizando Pyroxsulam e lodosulfurom-metílico, nas quantidades de 0, 75\%, 100\% e $125 \%$ da dose recomendada pelo fabricante aos 7 DAA, 14 DAA, e 21 DAA.

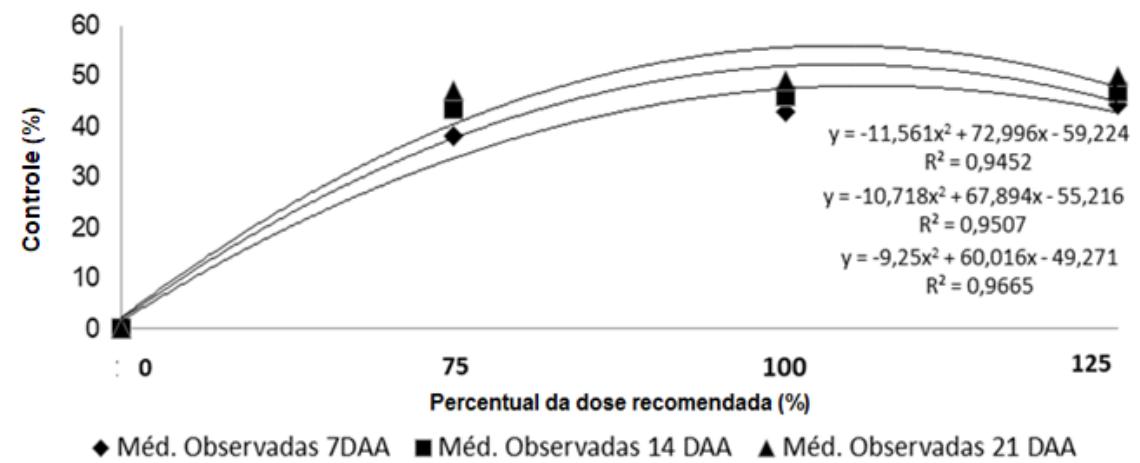

Fonte: elaborada pelos autores

\subsection{Controle de Lolium multiflorum L.}

Na avaliação do controle de azevém aos 7, 14 e 28 DAA, observou-se que o herbicida Pinoxadene apresentou a melhor resposta, enquanto que o controle menos efetivo foi obtido com herbicida lodosulfurom-metílico (Tabela 4). 
Tabela 4 - Percentual de controle de azevém aos 7, 14, 21 e 28 dias após a aplicação (DAA) dos herbicidas

\begin{tabular}{l|c|c|c|c}
\hline \multicolumn{1}{c|}{ Herbicidas } & DAA & 14 DAA & 21 DAA & 28 DAA \\
\hline Testemunha & $0 \mathrm{a}$ & $0 \mathrm{a}$ & $0 \mathrm{a}$ & $0 \mathrm{a}$ \\
\hline lodosulfurom-metílico & $16,5 \mathrm{~b}$ & $26,7 \mathrm{~b}$ & $45,4 \mathrm{~b}$ & $46,3 \mathrm{~b}$ \\
\hline Clodinafope-propargil & $24,8 \mathrm{c}$ & $35,8 \mathrm{c}$ & $49,7 \mathrm{~b}$ & $59,8 \mathrm{c}$ \\
\hline Pyroxsulam & $30,5 \mathrm{~d}$ & $48,6 \mathrm{~d}$ & $50,0 \mathrm{~d}$ & $64,0 \mathrm{~d}$ \\
\hline Pinoxadene & $81,0 \mathrm{e}$ & $83,2 \mathrm{e}$ & $85,0 \mathrm{e}$ & $85,0 \mathrm{e}$ \\
\hline \multicolumn{1}{c|}{ CV \% } & 8,8 & 5,8 & 6,0 & 4,7 \\
\hline
\end{tabular}

Médias seguidas pelas mesmas letras não diferem entre si. Fonte: elaborada pelos autores

O herbicida Pinoxadene apresentou elevado controle aos 7 DAA, com 81,0\% de controle, com um leve aumento dessa porcentagem de controle ao longo das avaliações (Tabela 4). Os demais herbicidas apresentaram ação gradativa ao longo das avaliações. Entretanto, passados 28 DAA, observou-se que os percentuais de controle do azevém por esses herbicidas foram inferiores àquele obtido com o Pinoxadene aos 7 DAA. A utilizaçao de 100\% da dose recomendada pelo fabricante do herbicida Pinoxadene foi a melhor dose observada para o controle de azevém em trigo (Figura 02).

Figura 2 - Percentual de controle de azevém dos herbicidas avaliados, empregando $75 \%, 100 \%$ e $125 \%$ da dose recomendada pelo fabricante, aos 7 (A), 14 (B), 21 (C) e 28 (D) dias após a aplicação (DAA)

A

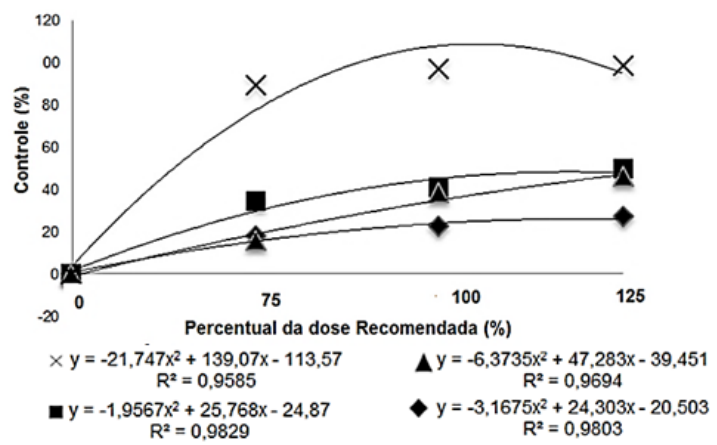

C

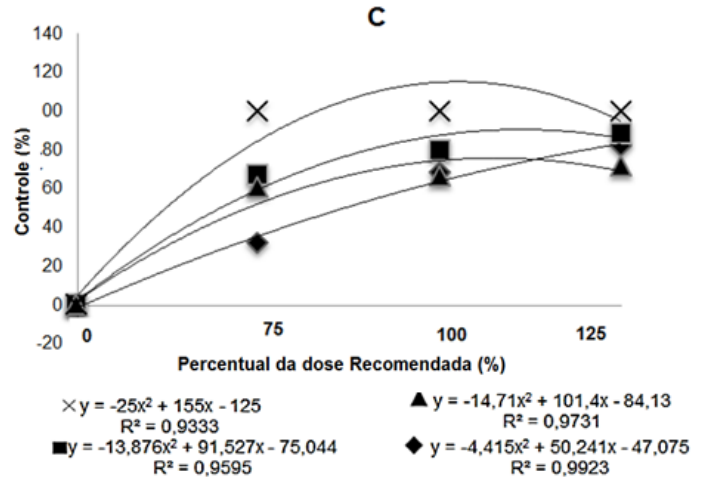

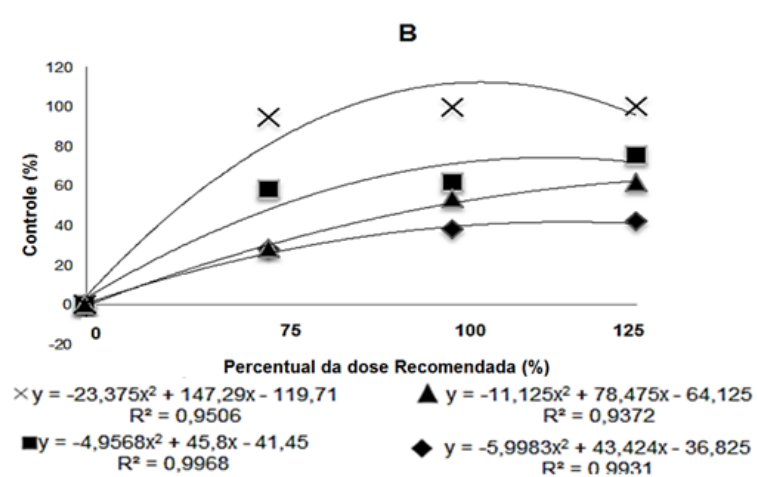

D

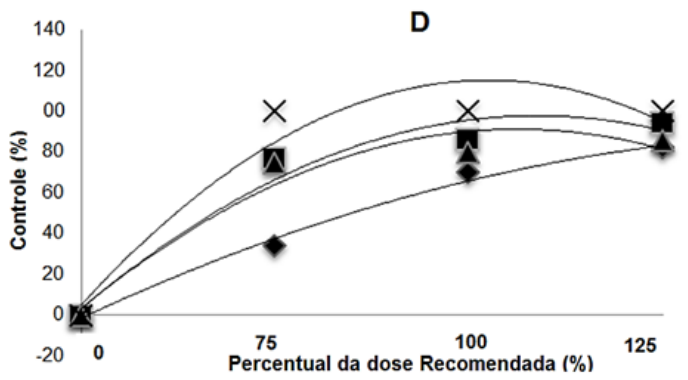

$x y=-25 x^{2}+155 x-125$

$R^{2}=0,9333$

(112,66x-91,828 $R^{2}=0,9493$
$\boldsymbol{\Delta} y=-17,124 x^{2}+114,74 x-94,373$

$R^{2}=0,9626$

- $y=-5,4568 x^{2}+55,468 x-51,37$ $R^{2}=0,991$

$\mathrm{X}$ Pinoxadene $\bullet$ lodosulfurom - metilico

Pyroxsulam $\boldsymbol{\Delta}$ Clodinafope- propargil

Fonte: elaborada pelos autores

Os resultados obtidos indicam que se deve preconizar a utilização dos produtos nas dosagens recomendadas pelos fabricantes e nas condições indicadas para a aplicação. $\mathrm{O}$ uso de subdoses repetidas pode levar a ocorrência de plantas resistentes, enquanto que doses superiores às recomendadas podem resultar em danos para a cultura e ao meio ambiente. 


\subsection{Avaliação da fitotoxidez}

Na avaliação de fitotoxidez realizada aos 07 DAA na cultivar TBIO Audaz, observou-se que o herbicida Pyroxsulam apresentou o maior percentual de fitotoxidez (clorose visual), seguido do herbicida lodosulfurom-metílico (Tabela 5). Os herbicidas Clodinafope-propargil e Pinoxadene não diferiram estatisticamente da testemunha, sem herbicida.

Tabela 5 - Percentual de clorose nas folhas de trigo, cultivares TBIO Audaz e TBIO Toruk, 07 dias após a aplicação dos herbicidas

\begin{tabular}{l|c|c}
\hline \multicolumn{1}{c|}{ Tratamentos } & TBIO Audaz & TBIO Toruk \\
\hline Testemunha & $0 \mathrm{a}$ & $0 \mathrm{a}$ \\
\hline Clodinafope-propargil & $0 \mathrm{a}$ & $0 \mathrm{a}$ \\
\hline Pinoxadene & $0 \mathrm{a}$ & $2,0 \mathrm{~b}$ \\
\hline lodosulfurom-metílico & $1,2 \mathrm{~b}$ & $1,0 \mathrm{a}$ \\
\hline Pyroxsulam & $2,5 \mathrm{c}$ & $2,6 \mathrm{~b}$ \\
\hline CV \% & 4,2 & 3,5
\end{tabular}

Médias seguidas pelas mesmas letras não diferem estatisticamente. Fonte: elaborada pelos autores

Na cultivar TBIO Toruk, a fitotoxidez também foi observada aos 7 DAA com o uso do herbicida Pyroxsulam, evidenciando maior clorose visual, não diferindo de Pinoxadene. A menor fitotoxidez foi observada com os herbicidas lodosulfurom-metílico e Clodinafope-propargil que não diferiram da testemunha sem herbicida. Para ambas as cultivares, não foi observado clorose visual nas avaliações aos 14, 21 e 28 DAA, sendo os valores iguais a zero.

Embora se tenha registrado fitotoxidez aos 7 DAA (Tabela 5), as mesmas foram consideradas leves, conforme a escala de EWRC (1964), (Tabela 2). Não foi observado necrose nas folhas e morte de plantas. Em trabalho semelhante, Lourenço \& Alencar (2016), observaram que o percentual de clorose foi mais evidente nas primeiras avaliações (14 DAA) e, posteriormente, foi constatada clorose igual a zero na cultivar de trigo CD-150.

Não foi observada diferença significativa na fitotoxidez para dose de 75\%. Na dose de 100\%, o herbicida Pyroxsulam apresentou a maior fitotoxidez, com o maior percentual de clorose das folhas (Tabela 6).

Tabela 6 - Percentual de clorose de folhas de trigo aos 07 dias após a aplicação de $100 \%$ e $125 \%$ da dose de herbicidas recomendada pelos fabricantes

\begin{tabular}{l|c|c}
\hline \multicolumn{1}{c|}{ Tratamentos } & Dose $100 \%$ & Dose $125 \%$ \\
\hline Testemunha & $0 \mathrm{a}$ & $0 \mathrm{a}$ \\
\hline Clodinafope-propargil & $0 \mathrm{a}$ & $0 \mathrm{a}$ \\
\hline Pinoxadene & $1,0 \mathrm{a}$ & $1,0 \mathrm{a}$ \\
\hline lodosulfurom-metílico & $0,8 \mathrm{a}$ & $3,8 \mathrm{~b}$ \\
\hline Pyroxsulam & $5,5 \mathrm{~b}$ & $3,8 \mathrm{~b}$ \\
\hline CV \% & 2,09 & 1,5 \\
\hline
\end{tabular}

Médias seguidas pelas mesmas letras não diferem estatisticamente. Fonte: elaborada pelos autores 


\subsection{Altura de plantas}

A presença de plantas invasoras é um fator que favorece o aumento da altura das plantas de trigo (RUBENICH et al., 2017), pois a redução da luminosidade causada pela mato-competição aumenta a estatura de plantas. Observou-se, aos 7 DAA dos herbicidas, que altura de plantas para ambas as cultivares foi maior no tratamento em que se utilizou Clodinafope-propargil (Tabela 7).

Tabela 7 - Altura de plantas (cm) das cultivares de trigo TBIO Audaz e TBIO Toruk aos 7 e 28 dias após a aplicação (DAA) dos herbicidas

\begin{tabular}{|c|c|c|c|c|}
\hline \multirow{2}{*}{ Tratamentos } & \multicolumn{2}{|c|}{7 DAA } & \multicolumn{2}{|c|}{28 DAA } \\
\hline & TBIO Audaz & TBIO Toruk & TBIO Audaz & TBIO Toruk \\
\hline Testemunha & $36,4 \mathrm{~b}$ & $35,0 \mathrm{~b}$ & $70,6 \mathrm{~b}$ & 59,4 a \\
\hline lodosulfurom - metílico & $34,4 a$ & $32,8 \mathrm{a}$ & $69,3 \mathrm{a}$ & 57,3 a \\
\hline Pyroxsulam & 35,5 a & 33,5 a & $71,0 \mathrm{~b}$ & 57,4 a \\
\hline Pinoxadene & 35,5 a & $34,5 b$ & $66,5 \mathrm{a}$ & 59,1 a \\
\hline Clodinafope - propargil & $38,1 \mathrm{c}$ & $37,6 \mathrm{c}$ & $68,3 \mathrm{a}$ & 59,7 a \\
\hline CV \% & \multicolumn{2}{|c|}{5,12} & \multicolumn{2}{|c|}{4,26} \\
\hline
\end{tabular}

Médias seguidas pelas mesmas letras não diferiram estatisticamente. Fonte: elaborada pelos autores

A limitação do crescimento do meristema apical do caule pode ser uma característica do herbicida. Além do herbicida Clodinafope-propargil apresentar maior percentual de controle de azevém em relação ao lodosulfurom-metílico (Tabela 4), ele não provocou redução na estatura das plantas de trigo aos 7 DAA, ao passo que lodosulfurom-metílico expressou essa característica (Tabela 7). No entanto, aos 28 DAA, a altura de plantas no tratamento com Clodinafope-propargil se igualou ao Pinoxadene e Iodosulfurom-metílico para a cultivar TBIO Audaz (Tabela 7). Na cultivar Toruk, não houve diferença entre os herbicidas e a testemunha para essa variável, mostrando maior possibilidade de recuperação desse material em relação à fitotoxidez causada pelos herbicidas pós-emergentes.

\subsection{Rendimento de grãos e componentes do rendimento}

Não houve diferença estatística no rendimento de grãos entre as cultivares estudadas. 0 peso de mil grãos (PMG) e o peso hectolitro (Ph) foram maiores para a cultivar TBIO Toruk quando comparada à cultivar TBIO Audaz (Tabela 8), sendo essa variação atribuída a cultivares, visto que neste trabalho a utilização dos herbicidas não apresentou incrementos na variável Ph. De acordo com Mennan e Zandstra (2005), há diferença entre cultivares de cereais em tolerar a competitividade com invasoras, além das condições edafoclimáticas da região, possibilitando a variação nos parâmetros de rendimento de grãos.

Tabela 8 - Peso de mil grãos (PMG) e peso hectolitro (Ph) das cultivares de trigo TBIO Audaz e a TBIO Toruk

\begin{tabular}{|c|c|c|}
\hline Cultivar & PMG (g) & Ph \\
\hline TBIO Audaz & $30,2 \mathrm{a}$ & $71,7 \mathrm{a}$ \\
\hline TBIO Toruk & $33,8 \mathrm{~b}$ & $72,3 \mathrm{~b}$ \\
\hline CV $\%$ & 5,7 & 1,9 \\
\hline
\end{tabular}

Médias seguidas pelas mesmas letras não diferem estatisticamente. Fonte: elaborada pelos autores

O PMG foi superior à testemunha no tratamento com o herbicida Pinoxadene. Entretanto, não houve diferença para os demais tratamentos (Figura 9). O rendimento de grãos foi maior nos tratamentos em que se utilizou os herbicidas lodosulfurom-metílico e Pinoxadene. O fato de os dois herbicidas apresentarem maior percentual de clorose não restringiu o rendimento de grãos da cultura. 
Tabela 9 - Peso de mil grãos (PMG) e rendimento de grãos (sc ha-1) de trigo em função dos herbicidas testados

\begin{tabular}{l|c|c}
\hline \multicolumn{1}{c|}{ Herbicidas } & PMG & Rend. (sc ha ${ }^{-1}$ ) \\
\hline Testemunha & $31,0 \mathrm{a}$ & $33,5 \mathrm{a}$ \\
\hline Clodinafope $^{- \text {propargil }^{3}}$ & $31,8 \mathrm{a} \mathrm{b}$ & $36,4 \mathrm{~b}$ \\
\hline Pyroxsulam $^{2}$ & $31,9 \mathrm{a} \mathrm{b}$ & $38,5 \mathrm{~b}$ \\
\hline lodosulfurom $^{- \text {metílico }^{1}}$ & $32,5 \mathrm{a} \mathrm{b}$ & $41,7 \mathrm{c}$ \\
\hline Pinoxadene $^{3}$ & $32,6 \mathrm{~b}$ & $39,0 \mathrm{c}$ \\
\hline CV \% & 2,5 & 3
\end{tabular}

Médias seguidas pelas mesmas letras não diferem estatisticamente. Fonte: elaborada pelos autores

Observou-se um aumento linear no PMG com o aumento das doses dos produtos (Figura 3 A). Isso provavelmente deve-se à menor competição interespecífica, pois as doses mais altas também resultaram em maior controle de invasoras e, com isso, as plantas de trigo acumularam maior quantidade de fotoassimilados nos grãos.

Figura 3 - Peso de mil grãos (PMG) (A) e rendimento de grãos de trigo (sc ha-1) (B), de acordo com as doses dos herbicidas utilizados

A

B
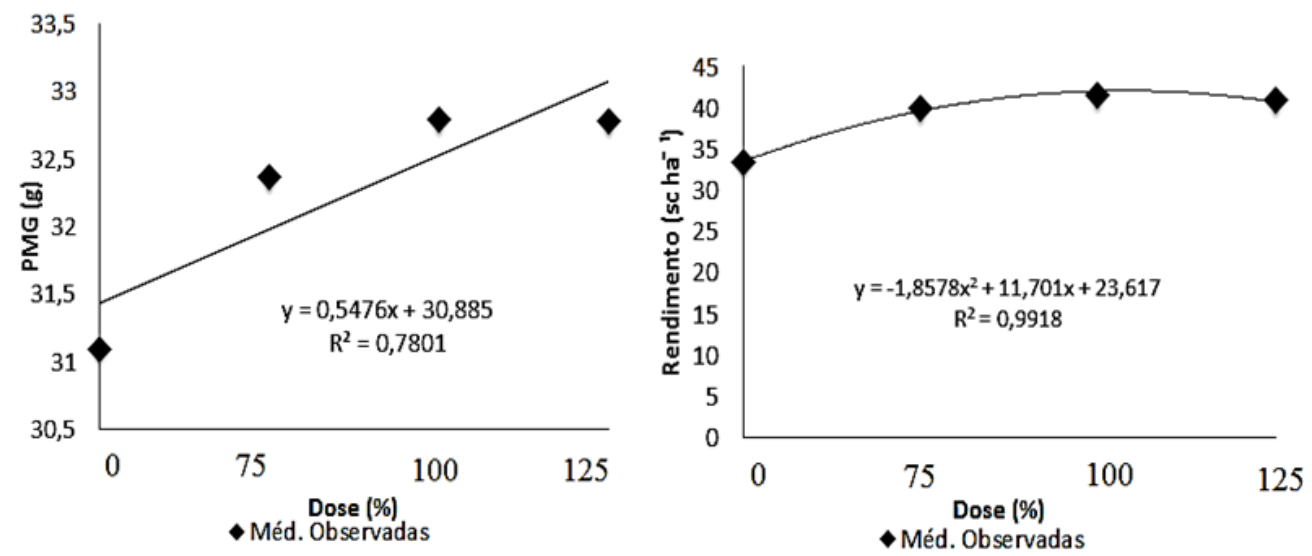

Fonte: elaborada pelos autores

O rendimento de grãos apresentou comportamento quadrático de acordo com as doses testadas (Figura 3 B). A máxima eficiência técnica foi obtida com a dose recomendada pelos fabricantes (100\%). Com a elevação da dose (125\%), houve uma estabilidade no rendimento, salientando a possibilidade de fitotoxidez e de danos ao meio ambiente nessas circunstâncias, além de elevar os custos de produção.

\section{Conclusão}

O herbicida Pinoxadene apresentou o melhor controle de azevém, enquanto que o herbicida Pyroxsulam apresentou o melhor controle de nabo.

A cultura do trigo apresentou sinais de fitotoxidez apenas aos 7 dias após a aplicação dos herbicidas, os quais foram considerados leves.

O rendimento de grãos de trigo foi superior nos tratamentos em que se utilizou os herbicidas lodosulfurom-metílico e Pinoxadene. 


\section{Referências}

AGOSTINETTO, D. et al. Alterações na Fotossíntese e Estresse Oxidativo em Plantas de Trigo Submetidas a Aplicação de Herbicidas. Planta Daninha, Viçosa,v. 34, n.1, p.1-9, Março 2016.

CECHIN, J. et al. Resistência de Biótipos de Nabo ao Herbicida lodosulfurom e Controle Alternativo. Planta Daninha, Viçosa, v. 34, n.1, p. 151-160, Jan./Mar 2016.

COSTA, L. O.; RIZZARDI, M. Habilidade competitiva de trigo em convivência com biótipos de Raphanus raphanistrum L. resistente e suscetível aos herbicidas inibidores de ALS. Ciênc. agrotec, Lavras, v.39, n.2, p.121-130, Mar/Abri 2015

DIEZ DE ULZURRUM,P.; LEADEN, M.I. Análisis de la sensibilidad de biotipos de Lolium multiflorum a herbicidas inhibidores de la enzima ALS, ACCasa y Glifosato. Planta Daninha Viçosa, v.30, n.3, p.667-673, Julho 2012.

EWRC, E. W. R. C.-. Report of the 3rd and 4th meetings of EWRC - Committee of methods in Weed Research. Weed Res, Oxford, v. 4, n.1, p. 88, 1964.

Afonso Ferreira, Antônio Alberto, Lino Roberto. CNPA EMBRAPA. EMBRPA/PRODUTOS, 2005. Disponivel em: <http://www.cnpa.embrapa.br/produtos/algodao/publicacoes/trabalhos cba5/336.pdf>. Acesso em: 16 de setembro 2018.

IBGE - Instituto Brasileiro de Geografía e Estatística, Levantamento Sistemático da Produção Agrícola - LSPA janeiro 2017. Disponivel em: <https://www.ibge.gov.br/estatisticas-novoportal/economicas/agricultura-e-pecuaria/9201-levantamento-sistematico-da-producao-agricola.html>. Acesso em: 29 janeiro 2018.

INMET - Intstituto Nacional de Meteorologia. INMET, Condições diárias, publicado em 2017. Disponivel em: <http://www.inmet.gov.br/portal/>. Acesso em: 24 fevereiro 2018.

LAMEGO, P. F. et al. Alterações morfológicas de plântulas de trigo, azevém e nabo quando em competição nos estádios iniciais de crescimento. Planta daninha, Viçosa, v.33, n. 1, p. 13-22, 2015.

LOURENÇO, E.; ALENCAR, J. R. D. C. C. ESTUDO DA FITOTOXIDADE DE HERBICIDAS APLICADOS EM PÓS EMERGÊNCIA NA CULTURA DO TRIGO, Revista Iniciare, Campo Mourão, v. 1, m.1, p. 79-90, julio 2016.

MARIANI, F. et al. HERANÇA DA RESISTÊNCIA DE Lolium multiflorum AO IODOSULFURONMETHYL. Planta Daninha, Viçosa-MG, v. 33, n. 2 p. 351-356, 2015.

MARIANI, F. et al. Herança da Resistência de Lolium multiflorum ao lodosulfuron-Methyl Sodium, Planta Daninha, Viçosa, v. 33, n.2, p. 351-356, junho 2015.

MENNAN, H.; ZANDSTRA, B. H. Influence of wheat rate and cultivars on competitive ability of Bifra (Bifora radians). Weed Technol, v. 19, n. 2, p. 128-136, 2005.

RUBENICH, R. et al. Efeito da redução de luz na seletividade a herbicidas e rendimento, Revista Brasileira de Herbicidas, Itaqui, RS, v. 16, n. 4, p. 296-306, dez 2017.

SILVA, A. A. B. et al. Weed Interference Periods in Early Wheat in the Midwest of Paraná. Planta daninha, Viçosa, v.34, n.2, p. 291-298, 2016. 
TANVEER, A. et al. O Uso do Sulfato de Alquil Éter na Melhora da Eficácia de Herbicidas Contra a Ançarinha-Branca e a Corriola na Cultura do Trigo, Planta daninha, Viçosa, v. 35, n.2, p. 1-10, janeiro 2018.

ZELAYA, I. A.; OWEN, M. D. K.; VANGESSEL, M. J. Inheritance of evolved glyphosate resistance in Conyza canadensis (L.). Theor. Appl. Genetics, v. 110, n.2, p. 58-70, 2004. 